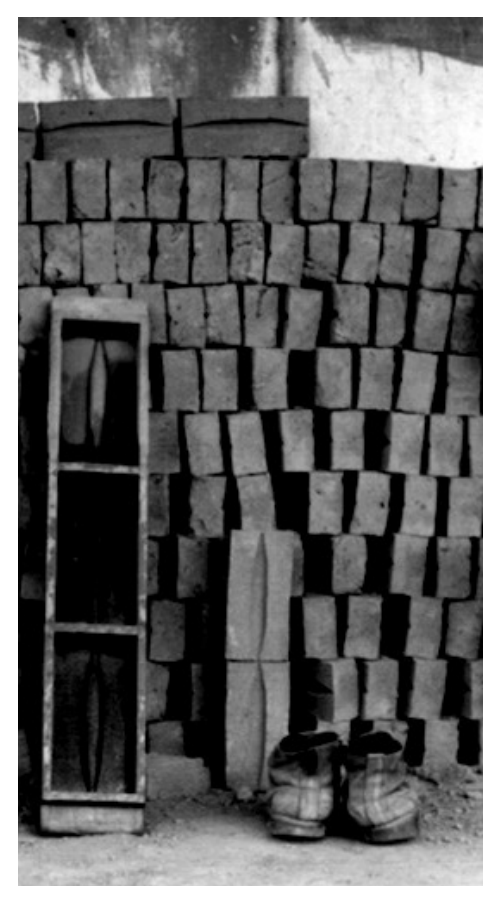

\title{
A atualidade do debate sobre autonomia universitária
}

Renato de Oliveira ${ }^{1}$

OLIVEIRA, R. The current nature of the debate on university autonomy. Interface _ Comunicação, Saúde, Educação, v.3, n.4, 1999.

Within the present context of the internal and external crisis affecting the institution of higher education, the historical and institutional experience of Brazilian universities is resumed, to debate the issue of autonomy. The fundamental aspects of a public university autonomy project in our country are analysed, contraposing the government project on one hand and the higher education community's project on the other.

KEY WORDS: university, autonomy

Retorma-se a experiência histórico-institucional da universidade brasileira para debater a questão da autonomia no contexto atual da crise interna e externa da instituição universitária. Contrapondo o projeto da comunidade universitária ao projeto governamental, são analisados aspectos fundamentais para um projeto de autonomia da universidade pública em nosso país.

PALAVRAS-CHAVE: universidade, autonomia.

${ }^{1}$ Professor da Universidade Federal do Rio Grande do Sul (UFRGS), da Universidade de Brasília (UnB) e presidente da Associação Nacional do Ensino Superior (ANDES) -Sindicato Nacional. 
Diferentemente de há alguns anos atrás, quando a questão da autonomia universitária não ia muito além das palavras de ordem de algumas "minorias ideológicas", hoje a questão ocupa não apenas a comunidade universitária como também os grandes meios de comunicação e o próprio governo, até então seu grande adversário. O que mudou? Muita coisa.

O fato de, há até não muito tempo, a questão da autonomia ser tema de exegeses jurídicas e apanágio de grupos de esquerda e não muito mais do que isto, tem muito a ver com a experiência histórico-institucional do sistema universitário brasileiro. Afinal, com algumas exceções, este surgiu como resultado de iniciativas diretas do Estado (leia-se Poder Executivo), o que marcou profundamente seu perfil institucional, estabelecendo limitações claras à sua capacidade de auto-governo. Se lembrarmos a "velha" experiência universitária brasileira, isto é, o período anterior à reforma imposta pela ditadura militar no início dos anos 70, o dogma da liberdade acadêmica, um dos fundamentos da autonomia universitária, tinha expressão institucional limitada à liberdade de cátedra, não alcançando a instituição universitária como um todo. Liberdade de cátedra, aliás, que dado o universo ideológico em que operavam a imensa maioria dos catedráticos, não ameaçava o conservadorismo reinante. O período posterior a 1970, ao abolir o sistema de cátedra, aboliu também o conceito de liberdade acadêmica. As inúmeras cassações de docentes por razões ideológicas e políticas mostraram que, doravante, não existiriam sequer garantias individuais para o exercício da liberdade de pensamento por parte dos professores.

Ora, a herança universitária que temos em mãos tem muito pouco a ver com a universidade anterior a 1970. Temos hoje uma instituição engessada, pretensamente democrática do ponto de vista das suas relações acadêmicas $e$ administrativas internas, mas que, na realidade, é uma instituição na qual o poder real, tanto acadêmico quanto administrativo, não está em seu interior. Entre outras coisas, a substituição da antiga cátedra pelos departamentos, se livrou a instituição do poder discricionário de professores muitas vezes mais preocupados com a preservação de privilégios do que com o avanço e a difusão do conhecimento, longe de significar democratização da vida acadêmica, burocratizou-a e despersonalizou-a. Quando um professor recém-egresso, muitas vezes sem pós-graduação, pode ser "chefe" de professores mais antigos, mais titulados e mais experientes, é porque o "chefe" nada decide. Apenas cumpre um ritual burocrático, liberando seus "subordinados" para, entre outras coisas, negociarem financiamento para seus projetos acadêmicos com instituições externas à própria universidade, sedes do verdadeiro poder no que respeita à pesquisa, por exemplo. Por outro lado, na pretensa democracia colegiada dos departamentos, e mesmo dos órgãos superiores de administração propriamente dita, qualquer dirigente universitário, bem como qualquer representante docente, técnicoadministrativo ou estudantil num órgão colegiado, sabe que o poder de decisão está no Ministério da Educação e Cultura/MEC, (quando não nos ministérios da área econômica ou da administração) e que uma simples portaria, um Aviso Ministerial ou um telefonema de um burocrata de terceiro escalão podem alterar ou determinar os mínimos detalhes da vida 
da instituição. Em suma, a universidade é heterônoma administrativa, financeira, científica e academicamente, em franca contradição com o que dispõe a Constituição de 1988.

Certamente esta heteronomia não se deve apenas ao gosto autoritário dos ideólogos do regime militar. Mais que isto, ela foi necessária para o desenvolvimento de um projeto institucional que buscava adequar a universidade às políticas globais da ditadura. Tais políticas, como se sabe, buscavam, sob o binômio Segurança e Desenvolvimento, o fortalecimento do "poder nacional" pelo fortalecimento da capacidade produtiva do país em setores considerados estratégicos para a expansão desse "poder", segundo a formulação característica da Escola Superior de Guerra. Ora, o fortalecimento da capacidade produtiva em setores como a indústria aeroespacial, a energia nuclear, as telecomunicações, a informática e a indústria bélica, entre outros, exigia um suporte tecnológico que não estava disponível no mercado internacional (além do que seria uma incoerência falar-se em poder nacional sem autonomia tecnológica nestes setores) e uma infraestrutura econômica e energética que viabilizasse o desenvolvimento das atividades por ele requeridas.

Nossa hipótese básica é de que as universidades públicas brasileiras, especialmente as federais, foram pensadas para responder à demanda de quadros e de conhecimento científico e tecnológico representada por esse projeto. Aliás, a configuração atual do sistema federal de ensino superior, em termos quantitativos, qualitativos e organizacionais, foi finalizada durante o período militar. Se o sistema institucional e de apoio financeiro à sua qualificação é anterior à ditadura, remanescendo ao governo de Juscelino Kubitschek, sua efetivação e consolidação é obra dos militares. Sobretudo, é nos investimentos na infra-estrutura de pósgraduação e aperfeiçoamento docente, bem como na infra-estrutura de pesquisa no interior das grandes universidades, que se seguiram à reforma de 1970, alavancando os resultados das iniciativas governamentais anteriores a 1964 (e anulando outras!), que está a origem do alto nível e do perfil de qualificação atual de muitas dessas instituições.

Deste ponto de vista, entendemos que, não só por sua generalização mas, sobretudo, por ter representado um projeto coerente e sistemático, a experiência das universidade federais é fundamental para pensarmos, hoje, a atualidade e os dilemas da autonomia universitária. De fato, os sistemas estaduais de ensino superior não conseguiram projetar um modelo capaz de se contrapor ao federal. O caso do sistema paulista, de longe o mais importante, é típico, inclusive por sua heterogeneidade interna. A USP, se é e continuará sendo a principal referência de qualidade acadêmica para grande número de universidades brasileiras, certamente não é um "modelo" a ser adotado. Por suas características, $e$ por fatores sobre os quais não cabe aqui nos alongarmos, é e continuará sendo, por muito tempo, uma universidade única. Quanto ao projeto da Unicamp, de uma universidade fortemente integrada ao sistema produtivo e empresarial, não só não produziu uma 
referência enquanto tal como ainda enfrenta sérios problemas de continuidade do seu projeto. Finalmente, a Unesp, em sua origem, não apresenta nenhuma originalidade: algumas dezenas de unidades isoladas que, encontrando dificuldades de viabilização econômica, passam a ser garantidas pelo Estado, sem que isto represente em sua origem um projeto acadêmico propriamente dito. Por outro lado, e como esperamos demonstrar ao longo deste artigo, a "autonomia" conquistada pelas universidades estaduais paulistas está longe de se configurar numa autonomia propriamente dita, não respondendo à maior parte das questões que se colocam hoje para as universidades públicas brasileiras.

Quanto às instituições privadas, seu perfil dispensaria maiores comentários. Caberia apenas referir que, dado o tipo de projeto seguido pelas instituições federais e à exiguidade dos sistemas estaduais em termos quantitativos, coube a elas responder à maior parte da demanda social por ensino superior, bem como às crescentes demandas de mercado por novos profissionais, principalmente no período de expansão econômica que se seguiu ao fim dos anos 60. Deixando de lado as exceções que confirmam a regra, seu perfil "acadêmico" expressa isto: trata-se de instituições que oferecem ensino de baixo custo e baixa qualificação para um mercado que, dada a condição de periférico, apresenta baixo nível de exigência quanto à competência média dos profissionais que absorve.

A emergência da questão da autonomia universitária liga-se, então, ao esgotamento do modelo oriundo da reforma de 1970. Esgotamento não apenas político - este, aliás, evidente. Afinal, a contestação ao Estado autoritário levaria compreensivelmente, como de fato levou, à contestação do modelo de universidade por ele gerado. É necessário reconhecermos, no entanto, que a contestação interna ao autoritarismo imanente à universidade pós-reforma não conseguiu ir além de seus aspectos exteriores (os métodos de escolha dos dirigentes, por exemplo), não chegando à crítica programática, a não ser eventual e episódica, dos sistemas internos de tomadas de decisão e divisão de

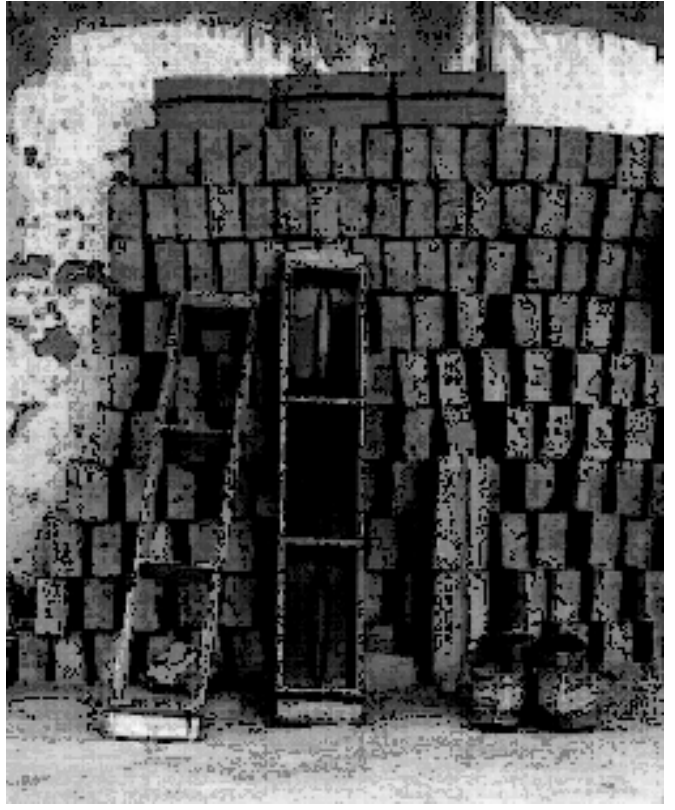
responsabilidades, muito menos a aspectos, comumente vistos como abstratos, relativos à ordenação jurídica de suas relações internas $e$ externas.

Mas há sobretudo um esgotamento econômico, configurado numa crescente disfuncionalidade do sistema universitário público. Entenderemos isto mediante um raciocínio simples: não havendo mais um projeto estatal de desenvolvimento, a universidade pensada para ser um dos seus instrumentos perde sua função. Esta disfuncionalidade econômica traduz-se numa crise de muitas facetas. Em primeiro lugar, a crise financeira. Há uma certa lógica no arrocho orçamentário das universidade federais: um governo que se comporta como 
intermediário dos interesses dos grandes conglomerados financeiros nacionais junto ao sistema produtivo nacional certamente não vê muita razão em investir num sistema universitário cuja lógica de funcionamento é, bem ou mal, voltada ao fortalecimento desse sistema produtivo. Mas há também uma crise ideológica difusa, manifestada na frustração das expectativas profissionais de milhares de professores, especialmente daqueles envolvidos diretamente com a pesquisa, que, após investirem anos em sua formação, vêem-se frente a uma instituição que não é capaz de formular uma política clara na qual eles possam se inserir, e frente a políticas governamentais que supõem o desmantelamento da instituição.

Mas, há também a crise própria das instituições estaduais de ensino superior. Heterogêneas na sua origem, apresentam capacidade efetiva ou potencial de excelência acadêmica no sudeste e sul do país, autonomizandose, em larga medida, das injunções políticas regionais. Na sua maioria, porém, encontram enorme dificuldade para definirem projetos acadêmicos capazes de orientar a ação institucional.

Este é o terreno sobre o qual emerge a exigência da autonomia universitária, implicando em projetos claramente distintos. De um lado, o projeto governamental, para quem autonomia significa, antes de mais nada, a possibilidade de diminuição dos encargos financeiros que o sistema universitário representa, liberando recursos para seus compromissos junto ao sistema financeiro internacional. Recentes declarações de responsáveis do MEC, adotando a tese da "auto-aplicabilidade" do artigo 207 da Constituição Federal reforçam essa proposta. Interpretada ao pé da letra, esta tese implica a supressão da normalização do sistema de ensino superior, liberando as instituições para a auto-gestão administrativa e financeira. Um dos resultados previsíveis, além da mercantilização das atividades de ensino, pesquisa e extensão, seria a regressão de muitas das atuais universidades à condição de Centros de Ensino Superior, tal como previsto na regulamentação do capítulo da Lei de Diretrizes e Bases da Educação/LDB, que trata de ensino superior. A autonomia neste caso, portanto, seria apenas financeira (com a correspondente autonomia administrativa), mantendo-se o essencial da tutela jurídico-política que caracteriza a relação das universidades com o Poder Executivo. Poderíamos comparar esta proposta com uma espécie de capitalismo à chinesa, no qual a liberdade de iniciativa no plano econômico não tem qualquer correspondência com a liberdade política.

De outro, o projeto da comunidade universitária. Mais que projeto, a comunidade universitária expressa hoje um conjunto de proposições, de variável grau de articulação, que demonstram, antes de tudo, o temor quanto ao futuro. Sequer os seus dirigentes têm uma posição comum. Há os que, temendo os riscos de uma autonomia sem compromissos claros por parte do governo, principalmente no que diz respeito ao financiamento, sonham com um sistema no qual possam gerir livremente seus recursos financeiros e humanos mas, na dúvida, defendem o status quo com algumas mudanças cosméticas e, sobretudo, mais recursos. Há também os que, duvidando da capacidade do sistema como um todo de tomar iniciativas em direção à autonomia, assumem o risco de defendê-la para suas respectivas 
universidades, escudados sobretudo na sua capacidade, real ou presumida, de gerar recursos por conta própria, sem os atuais entraves burocráticos e administrativos. Argumentam, não sem boa dose de razão, que suas instituições tocaram o teto da atual normalização jurídico-administrativa do sistema universitário, atingindo o limite possível de realizações neste quadro, o que não seria uma situação comum às demais. Manter esta normalização sobre suas respectivas instituições significaria, pois, regredir em relação ao patamar de qualificação acadêmica já alcançado, o que não seria sentido da mesma forma por instituições de menor nível de qualificação.

O corpo docente, por sua vez, certamente também não tem uma posição unívoca a respeito. Há os que, situados no topo da carreira da qualificação acadêmica e trabalhando em universidades melhor situadas do ponto de vista da sua interação com interesses econômicos os mais diversos, associam a autonomia a maiores oportunidades de fazer o que já fazem hoje: assessorias, prestações de serviço e cursos de "extensão" que possibilitam significativos acréscimos de renda pessoal. Para muitos, a autonomia seria uma espécie de realização da utopia do liberalismo econômico: o maior número possível de professores enriquecendo individualmente, pela livre alocação de suas capacidades profissionais e científicas no mercado, levaria ao "enriquecimento" da universidade como um todo.

Mas há também os que, seja porque situados nos extratos inferiores da carreira, seja por terem maiores dificuldades de acesso ao sistema de pósgraduação e pesquisa, seja, ainda, porque trabalhando em universidades de regiões periféricas, vêem na autonomia o caminho mais seguro para sua transformação em docentes de "segunda categoria". Não há dúvidas de que, em se tratando da proposta do governo, esses docentes estão cobertos de razão. Para muitos desses colegas, a manutenção do status quo, em que pese todas as suas mazelas, ainda é a melhor alternativa. Significa não só a garantia de estabilidade funcional, como a possibilidade de alimentarem uma expectativa de carreira e de aperfeiçoamento profissional.

Mas a questão da autonomia está posta. Sem qualquer exagero, podemos dizer que ela ascendeu ao status de "necessidade objetiva". Em outras palavras, se mantido o atual modelo de ensino superior, serão as aspirações mais profundas da sociedade - as aspirações por democracia, por justiça social e por soberania nacional - que estarão comprometidas.

Manter o modelo atual de ensino superior significa manter um sistema determinado por uma oferta exígua sem qualquer conexão qualitativa $e$ quantitativa com o perfil da demanda; manter a separação entre um ensino "de elite", minoritário e subvencionado pelo Estado, e um ensino "de massa" como livre oferta de mercado, reproduzindo o próprio dualismo que caracteriza a sociedade brasileira, uma universidade cuja capacidade de acompanhar o desenvolvimento científico que caracteriza a contemporaneidade resume-se a pequenos grupos, e completamente incapaz, enquanto instituição, de dirigir o esforço intelectual de seus docentes e pesquisadores para os problemas que desafiam a continuidade da sociedade brasileira. Este modelo, enfim, é insustentável.

Como enfrentar a questão? Para grandes males, grandes remédios. O 
problema deve ser enfocado individualizando-se quatro aspectos que, apesar de indissociáveis no todo da autonomia, exigem formulações e soluções específicas a cada um.

Em primeiro lugar, há o aspecto jurídico. É no plano jurídico que, obviamente, deita raízes o conjunto de normas reguladoras da relação Universidade - Estado: no nosso caso, relação de estrita subordinação. De fato, o modelo jurídico da autarquia, que caracteriza as universidades públicas, foi constituído para o exercício descentralizado de atividades que constituem atribuição do Estado, e não para o exercício autônomo de uma função que constitui um interesse público. O conceito de autonomia carece, entre nós, de conceituação jurídica, entre outras razões, pelo fato de a confusão entre o público e o estatal permanecer solidamente arraigada entre nós, malgrado as exaustivas demonstrações de compromisso com interesses privados/oligárquicos, de parte do Estado brasileiro, desde sempre. A designação de "autarquias especiais", com a qual já se procurou preservar as universidades das limitações inerentes ao regime autárquico, não resolveu o problema. É preciso, enfim, avançar uma formulação jurídica fundada na noção de exercício autônomo de uma função pública.

Em segundo lugar, há o aspecto do financiamento. Entendida a autonomia como direito fundamental, inerente à condição da universidade, e não como um simples direito instituído, cabe ao Estado garanti-lo mediante meios materiais e financeiros necessários à sua concretização. Podemos fazer uma analogia com o direito à vida: igualmente sendo um direito fundamental, desdobra-se numa série de outros direitos - ao trabalho, à educação, à alimentação, à saúde etc. - que implicam obrigações precisas por parte do Estado. Garantir, portanto, o direito à autonomia universitária, implica definir precisamente - legalmente - as obrigações estatais quanto ao financiamento das universidades públicas, garantindo-lhes os recursos necessários para suas atividades próprias (ensino, pesquisa e extensão) em níveis de qualidade compatíveis com o estágio atual do conhecimento humano, bem como a remuneração de seus servidores docentes e técnicoadministrativos.

Mas a questão do financiamento é muito mais complexa entre nós. Não se trata apenas de manter o atual sistema público, mas sobretudo de expandilo! Isto implica, antes de mais nada, aumentar as dotações do tesouro - o que supõe uma reforma fiscal que aumente a capacidade arrecadadora do

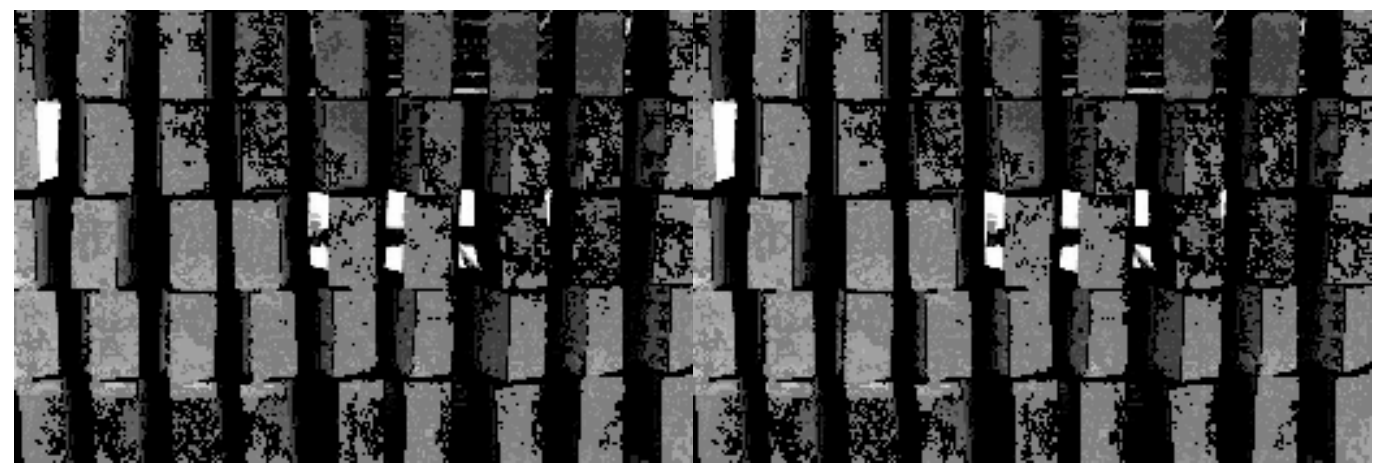


Estado, bem como uma profunda mudança na política de investimentos dos recursos arrecadados. Mas implica também - e esta seria uma abordagem nova - definir uma política de retorno, para a universidade, dos benefícios diretamente econômicos que os mais diversos segmentos da economia auferem diretamente da sua atividade. A valorização e rentabilidade do capital em setores de alta tecnologia, de produção e distribuição de energia, da agricultura etc., seria infinitamente menor se não fosse a atividade da universidade, tanto em pesquisa quanto em formação de recursos humanos. O que a universidade tem ganho com isto até agora? Nada - salvo em convênios específicos voltados para atividades específicas diretamente ligadas aos interesses de tais setores. Porque não se estabelece um sistema de taxação sobre a rentabilidade do capital em alguns setores da economia, cujos recursos fossem geridos autonomamente pelas universidades, segundo um plano estratégico de expansão de suas atividades? Nesta linha de raciocínio, poderíamos pensar inúmeras formas de obtenção de recursos (por exemplo, um percentual do imposto de renda das pessoas físicas $e$ jurídicas) que, significando o compromisso da sociedade para com a universidade e, portanto, com seu próprio futuro, aliados ao aumento das dotações estatais, garantiriam uma expansão do ensino público e gratuito em níveis aptos a colocar a sociedade brasileira no patamar da "sociedade do conhecimento", que caracterizará as sociedades desenvolvidas no próximo século.

Em terceiro lugar, há o aspecto da gestão e da avaliação. Uma universidade autônoma é uma universidade que, liberada dos entraves burocráticos da administração estatal, é também uma universidade capaz de estabelecer relações vivas com a sociedade que a mantém e a valoriza, integrando os problemas desta sociedade ao seu próprio planejamento. Este é sobretudo um problema de gestão. A sociedade civil organizada, bem como o Poder Público, a ela devem ter acesso direto, como integrantes $e$ responsáveis pelo sistema. Não basta apenas a transparência: o sistema de gestão da universidade (seja de cada instituição isoladamente, seja do sistema como um todo) deve ser um fórum onde os diversos interesses da sociedade civil se encontrem e se submetam a uma lógica mutuamente compartilhada de formulação do interesse público. Assim, atuando no seu campo específico, a universidade autônoma se situará no núcleo mesmo dos processos de formação pública das vontades políticas de uma sociedade democrática, no núcleo de constituição de uma cultura democrática $e$ solidária. É também no âmbito da gestão, assim concebida, que se definirão os mecanismos de avaliação, cujo compromisso não será o da competência abstrata dos padrões científicos primeiro-mundistas, mas a competência intelectual e científica na abordagem e solução dos nossos problemas. Finalmente, é no âmbito da gestão que se definirão os parâmetros da administração financeira e de recursos humanos que, assegurando os direitos da comunidade universitária, sobretudo os inerentes à função pública por ela desempenhada, asseguram também a crítica ao corporativismo.

E, "last but not least", é necessário desenvolver mecanismos de controle público sobre o ensino privado. O Brasil não é apenas um dos países com 
maior índice de privatização do ensino superior (sexto no ranking mundial, enquanto os EUA são o vigésimo), como é um dos poucos sem qualquer regulamentação específica sobre o setor. Os resultados desta situação dispensam comentários. Ora, qualquer regulamentação da autonomia universitária que não restabeleça o princípio de que a educação superior (bem como a educação em geral) é antes de tudo um bem público, independentemente de se realizar numa instituição estatal ou privada, estará destinada ao fracasso.

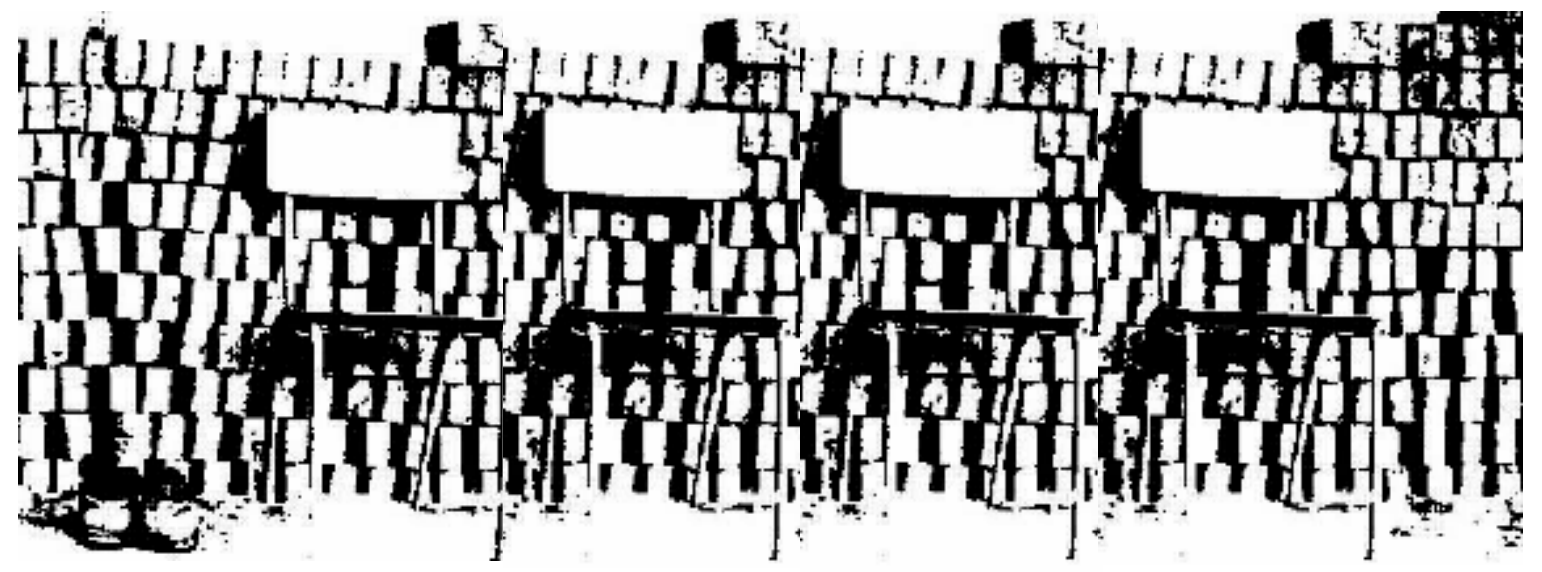

OLIVEIRA, R. La actualidad del debate sobre autonomía universitaria. Interface Comunicação, Saúde, Educação, v.3, n.4, 1999.

Se parte de la experiencia histórica de la universidad brasileña para debatir la cuestión de la autonomía en el contexto actual de crisis de la institución. Contraponiendo el proyecto de la comunidad universitaria al proyecto gubernamental, se analizan aspectos fundamentales para un proyecto de autonomía de la universidad pública en Brasil.

PALABRAS-CLAVE: universidad; autonomía. 


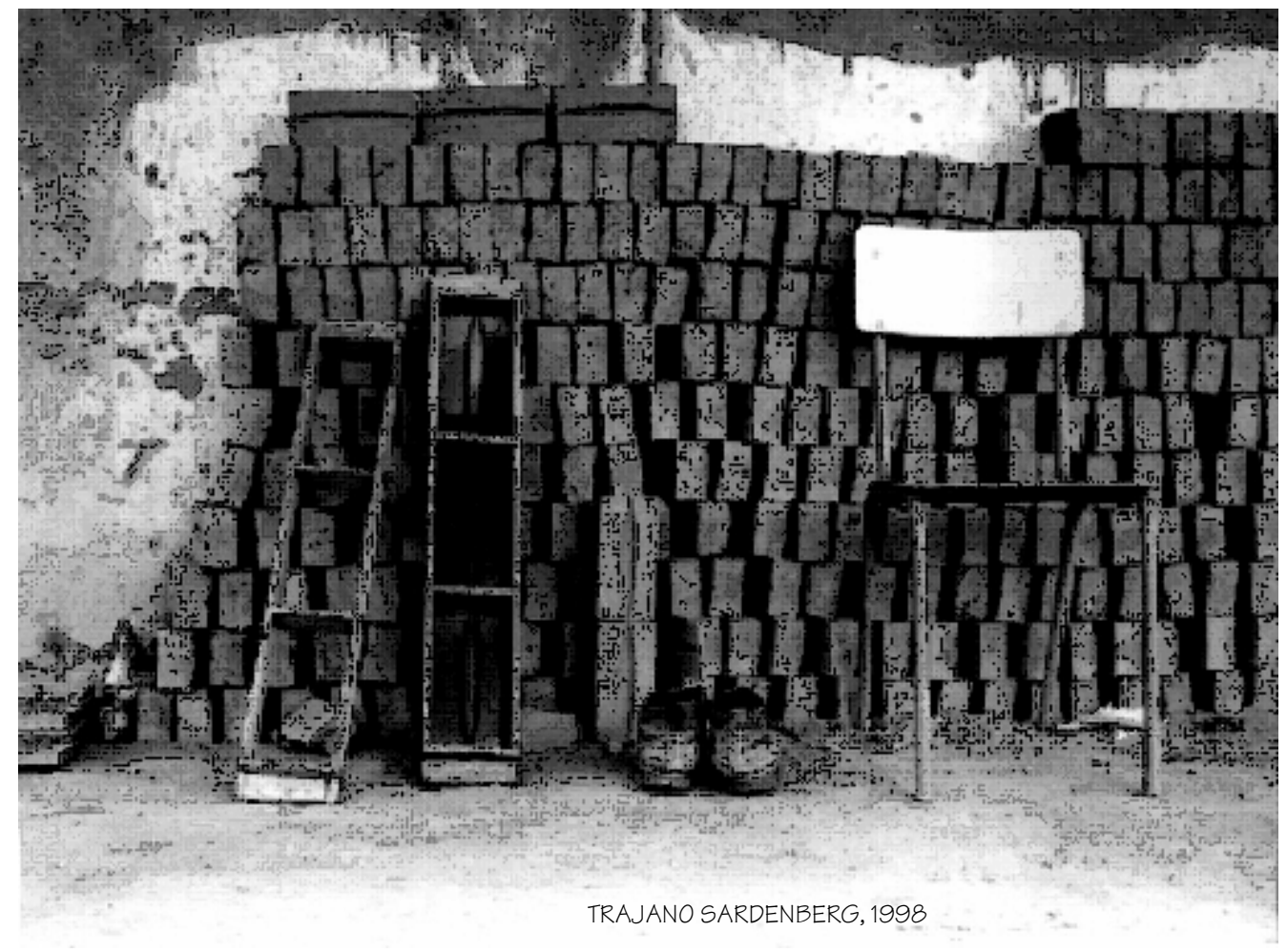

62 Interface - Comunic, Saúde, Educ 4 